\title{
Different Frequencies of Angiotensin-converting Enzyme Genotypes in Older Hypertensive Individuals
}

Brian J. Morris, Robert Y. L. Zee, and Andrew P. Schrader

Molecular Biology \& Hypertension Laboratory, Department of Physiology, School of Medicine, The University of Sydney,

N.S.W. 2006, Australia

\begin{abstract}
The frequency of the $D$ allele of an insertion/deletion (II $D$ ) polymorphism of the angiotensin I-converting enzyme (ACE) gene has been reported to be elevated in myocardial infarction and other patients. We therefore hypothesized that death rate of $D D$ individuals should be increased in the population as a whole and this should be evident as a decrease in $D D$ frequency with age. This hypothesis was tested in 118 Caucasian subjects who were already at high risk of cardiovascular events by having severe, early onset, familial hypertension (HT). A group of 196 age-, sex- and body mass index-matched normotensives (NTs) was used as a control. In the NT group $I I, I D$, and $D D$ genotype frequencies were similar for different age groups. $D D$ frequency was 0.42 in NTs, but in HTs was $0.28,0.26$, and 0.10 for the age groups $<50,50-59$, and $\geq 60 \mathrm{yr}$, respectively. Corresponding $D$ allele frequencies were $0.52,0.46$, and 0.40 in the respective age groups of HTs, compared with 0.61 in NTs (by $\chi^{2}$-analysis, $P=0.1,0.047$, and 0.0006 , respectively). In HTs aged $\geq 60, D D$ frequency was only $14 \%$ of expected. Plasma ACE activity tracked similarly with $I / D$ genotype in HTs $(P$ $=0.027 ; n=35)$ as in NTs $(P=0.0001 ; n=94)$ and Michaelis constant was identical for $D D$ and $I I$. Neither blood pressure, body mass index, nor sex bore any relationship with IID genotype. In conclusion, in a group of severely HT patients not selected for cardiac pathology, there appeared to be a marked, selective decrease, in subgroups of increasing age, in frequency of the $A C E D D$ genotype. One possibility suggested by this data might be that $D D$ increases risk of premature death, at least in HTs who have two HT parents. (J. Clin. Invest. 1994. 94:1085-1089.) Key words: cardiovascular disease $\cdot$ cross-sectional study $\bullet$ survival
\end{abstract}

\section{Introduction}

Angiotensin I-converting enzyme (ACE) ${ }^{1}$ (kininase II, EC 3.4.15.1) is widely distributed in the body. Its major recognized

Address correspondence to Brian J. Morris, DSc, Molecular Biology \& Hypertension Laboratory, School of Medicine, Department of Physiology, Building F13, The University of Sydney, N.S.W. 2006, Australia.

Received for publication 13 January 1993 and in revised form 20 May 1994.

1. Abbreviations used in this paper: $\mathrm{ACE}$, angiotensin I-converting enzyme; BMI, body mass index; $D$, deletion allele; DBP, diastolic blood pressure; HT, hypertension/hypertensive; $I$, insertion allele; MI, myocardial infarction; NT, normotensive; SBP, systolic blood pressure.

J. Clin. Invest.

(c) The American Society for Clinical Investigation, Inc.

0021-9738/94/09/1085/05 \$2.00

Volume 94, September 1994, 1085-1089 functions are the conversion of angiotensin I to the vasoactive, antinatriuretic octapeptide angiotensin II, and the inactivation of kinins, which have vasodilator and natriuretic properties (1). $\mathrm{ACE}$ is an ectoenzyme located in the plasma membrane of various types of cells, including endothelial cells of all vascular beds, cells of absorptive epithelia such as the renal proximal tubule, and other epithelia, including those in the brain, with particularly high concentrations in the choroid plexus, and is also found in biological fluids such as plasma and cerebrospinal fluid (2).

Plasma ACE concentration is stable in a given individual, but varies between different subjects (3) and displays an intrafamilial correlation that is contributed by a major gene effect (4). ACE is encoded by a $21-\mathrm{kb}, 26$ exon gene (5) located on chromosome 17 at q23 (6). A polymorphism of the ACE gene has been described and involves the insertion/deletion of a 287bp Alu repetitive sequence, in reverse orientation, near the $3^{\prime}$ end of intron $16(7,8)$. Plasma (7) and tissue (9) ACE concentration has been found to track with the deletion $(D)$ allele of the $I / D$ polymorphism, such that plasma values are $D D>I D>I I$, and the polymorphism is itself a neutral marker for a yet-to-beidentified closely linked variant responsible for level of ACE activity in plasma (10).

In a recent case-control study, the frequency of the $D D$ genotype was found to be elevated in geographically separated populations of French and Irish Caucasian patients who had had a myocardial infarction (MI) (11). That the $D D$ genotype contributes to fatal events, rather than nonfatal events or survival of MI, was supported by a subsequent report of association with parental history of fatal MI (12). Since then, other groups have reported an elevation in $D D$ genotype frequency in 101 MI patients from Japan (13), as well as in 112 Caucasian patients with idopathic-dilated cardiomyopathy (14), 102 with ischemic-dilated cardiomyopathy (14), 25 with hypertrophic cardiomyopathy who had a strong family history of sudden cardiac death (15), and 32 Japanese patients with restenosis after emergency percutaneous transluminal angioplasty (16).

In the Cambien study, the prevalence of hypertension (HT) and the blood pressure (BP) of a control, non-MI group was similar for each $I / D$ genotype (11). Because many of their MI patients were receiving drugs likely to affect BP, Cambien et al. were unable to define a normotensive (NT) low-risk group and so did not test whether $D D$ frequency was higher, the same, or lower with respect to this particular risk factor by itself. In relation to other risk factors, however, they found $D D$ genotype was especially frequent in MI patients regarded as low-risk according to their BMI and plasma ApoB or total cholesterol, but for high- and low-risk groups defined according to median cigarette consumption results were similar. Thus the finding of higher $D D$ in MI patients formerly considered to be at low risk according to common criteria was demonstrated for some of the common risk factors, but BP was not tested. A possible 
Table I. Demographic Characteristics of the Study Groups

\begin{tabular}{lcc}
\hline & HT & NT \\
\hline Total number of subjects & 118 & 196 \\
Male/female & $51 \% / 49 \%$ & $58 \% / 42 \%$ \\
Age (yr) & $52 \pm 13$ & $46 \pm 10$ \\
BMI (kg/m ${ }^{2}$ ) & $25 \pm 4$ & $25 \pm 4$ \\
Proportion with BMI $\geq 26 \mathrm{~kg} / \mathrm{m}^{2}$ & $32 \%$ & $36 \%$ \\
SBP (mmHg)* & $170 \pm 21$ & $115+10^{\ddagger}$ \\
DBP (mmHg)* & $110 \pm 16$ & $72 \pm 7^{\ddagger}$ \\
Total cholesterol (mmol/liter) & $5.6 \pm 1.1$ & $4.7 \pm 1.0^{\ddagger}$ \\
HDL cholesterol (mmol/liter) & $0.98 \pm 0.65$ & $0.77 \pm 0.07^{\ddagger}$ \\
Triglyceride (mmol/liter) & $2.7 \pm 1.5$ & $2.2 \pm 1.4^{\ddagger}$ \\
LDL cholesterol (mmol/liter) & $3.3 \pm 1.1$ & $2.9 \pm 0.8^{\ddagger}$
\end{tabular}

Values shown are mean \pm SD. * SBP and DBP values for HTs were those prior to treatment. ${ }^{\ddagger} P<0.01$ by Student's $t$ test, where hyperlipidemia is a common feature of HT (39).

interpretation of their data is lower post-MI survival of individuals at high risk by the criteria they used, when compared with post-MI survivors who were at low risk by these criteria, since this might leave a higher residue of post-MI patients having the single putative risk factor of $D D$ genotype in the study group employed. Interestingly, in a study of Japanese MI patients, significantly elevated $D D$ frequency was seen in both low and, to a lesser extent, high-risk groups, defined by similar criteria (13). Moreover, in a Norwegian study, not only was $D D$ higher in MI patients with a family history of MI (17), but in male high-risk patients, defined as in the Cambien study, $D D$ was decreased, with the suggestion that this could have reflected preferential loss from the high-risk group (18).

If the $D D$ genotype is a significant risk factor for MI or other causes of premature death, then one would expect the frequency of the $D D$ genotype to decrease with age in the general population. In contrast, polymorphisms at genetic loci that carry no selective advantage or disadvantage should exhibit frequencies that remain constant throughout life. However, given that the death rate from heart attack is $0.1 \%$ in $20-69$ yr-old Caucasians in our region (19), demonstration of a decrease in $D D$ genotype frequency in a general population would require a study group of considerable size. The effect of BP on the $D D$ genotype is, moreover, not known. We therefore decided to test the hypothesis using a specially selected group who were at high risk of cardiovascular events by being the affected offspring of parents who both had essential HT and who themselves had an early onset, severe form of this disease.

\section{Methods}

Subjects. These were 118 Caucasian HTs who had two HT parents and a control group of 196 NT subjects whose parents were NT past the age of $50 \mathrm{yr}$. Virtually all were volunteers. Further details of ascertainment and other information have been described previously (20-29). Table I shows demographic parameters for each group. Diastolic blood pressures (DBPs) of all HTs were $\geq 100 \mathrm{mmHg}$ and of all NTs were $<90 \mathrm{mmHg}$. Age distribution of HTs (22-82 yr: male, 22-69; female, 26-82) and NTs (30-71 yr) was similar: For the age groups $<50$, 50-59 and $\geq 60 \mathrm{yr}$, proportions of subjects were 46,19 , and $35 \%$, respectively, for HTs, and were 65,26 , and $15 \%$ for NTs. In the HT group there were no males older than 69 , whereas there were 7 females.
All of the HTs had been diagnosed with HT prior to age 54, the mean being $32 \pm 7 \mathrm{SD}$ yr and was similar for each age group and $I / D$ genotype. Among NTs, death from heart attack would be less than the rate of $0.1 \%$ for the population as a whole in the age range of our control group (19), since the risk factor of "hypertension" was absent. Given that death from heart attack in Australians aged 60-70, far exceeds that in younger age groups (19), $<1 \%$ of a NT group aged $<71 \mathrm{yr}$ would have been expected to have died of heart attack, which for a group of 196 subjects would represent $<2$ individuals, i.e., would be undetectable. We noticed, moreover, that $<10 \%$ of HTs had two HT parents, as would be expected for a disease that affects 1 in 5 adults, since the chance of any person having two HT parents would be $1 / 5 \times 1 / 5 \times 1 /$ $2=1$ in 50 , i.e., $2 \%$ of adults, or $10 \%$ of HTs. Thus our HT study population was a select subset.

Materials and experimental protocols. Genotypes for the I/D polymorphism were determined as described previously $(8,22)$. Plasma ACE activity and ACE kinetic measurements were made using an ACE activity radioassay kit (Hycor Biomed. Inc., Portland, ME), with substrate concentrations for the kinetic assays being set at 1.6, 3.2, 4.8, 6.4, and $8.0 \mu \mathrm{mol} / \mathrm{ml}$.

Statistical analyses. Genotype data were assigned to each age group and values for each age category in the NT group were then tested for deviation from those for the NT group as a whole by $\chi^{2}$ analysis. Once it was established that no significant difference existed, the values for the whole of the NT group were then compared, in the same way, with values for each age category of the HT group.

\section{Results}

Allele frequencies in different age groups. In the NT group, $D$ allele frequency was similar for each age group, viz. 0.59, 0.68, and 0.64 in subjects aged $<50,50-59$ and $\geq 60 \mathrm{yr}$, respectively $\left(\chi^{2}<0.5, P>0.5\right.$, when $I / D$ values for the respective age groups were compared with values for the whole of the NT group). Moreover, the frequencies observed in the NT group closely resembled those reported in the literature for the $I / D$ polymorphism in other healthy Caucasian populations $(7,8,10$, 30-32), and NT genotype frequencies did not differ significantly from values of $30 I I, 93 I D$, and $73 D D$ predicted from the Hardy-Weinberg equation.

In sharp contrast to results for the NT group, I/D allele, and genotype frequencies of each age group of HTs showed either no significant difference ( $<50 \mathrm{yr}$-old age group), a small statistical difference (50-59 yr-old age group), or a highly significant difference ( $\geq 60$ yr-old age group) when compared by $\chi^{2}$ analysis to values for the whole of the NT group (Table II). Furthermore, $\chi^{2}$ analysis of $D D$ frequency of each age group between the HT and NT groups also showed a significant difference $\left(\chi^{2}\right.$ 2 d.f. $=15.5, P=0.03$ ).

Allele frequencies for polymorphisms at 12 other loci studied previously $(20,21,23-29)$ showed no change with age in either the NT or HT group (data not shown). In addition, genotype frequencies for these variants obeyed Hardy-Weinberg equilibrium in both the NT and HT groups, with the exception of one which has been shown previously to be associated with HT $(21,26,29)$.

The different results for each of the HT age groups can most logically be interpreted as reflecting a marked, progressive decrease in frequency of the $D D$ genotype with age. Such an apparent loss of the $D D$ genotype would occur if $D D$ carried an increased risk of premature death. Indeed, we can think of no other reason besides this which would explain these results. Based on NT allele frequencies, the Hardy-Weinberg formula predicts genotype frequencies of $15.2 \% \mathrm{II}, 47.6 \% \mathrm{ID}$, and $37.2 \%$ 
Table II. Genotype and Allele Frequencies of the I/D Polymorphism of the ACE Gene in 196 NT Subjects and in 118 Patients with Severe, Familial HT, Categorized by Age

\begin{tabular}{|c|c|c|c|c|c|c|c|c|c|}
\hline & \multicolumn{3}{|c|}{ Genotype frequencies } & \multirow[b]{2}{*}{$\chi^{2}$} & \multirow[b]{2}{*}{$P$} & \multicolumn{4}{|c|}{ Allele frequencies } \\
\hline & II & $I D$ & $D D$ & & & $I$ & $D$ & $\chi^{2}$ & $P$ \\
\hline Normotensives & $\begin{array}{c}37 \\
(19 \%)\end{array}$ & $\begin{array}{c}77 \\
(39 \%)\end{array}$ & $\begin{array}{c}82 \\
(42 \%)\end{array}$ & 一 & - & 0.39 & 0.61 & 一 & - \\
\hline \multicolumn{10}{|c|}{ HTs by age-group } \\
\hline $\begin{array}{l}<50 \mathrm{yr} \\
\text { (54 patients) }\end{array}$ & $\begin{array}{c}13 \\
(24 \%)\end{array}$ & $\begin{array}{c}26 \\
(48 \%)\end{array}$ & $\begin{array}{c}15 \\
(28 \%)\end{array}$ & 3.3 & 0.20 & 0.48 & 0.52 & 3.0 & 0.10 \\
\hline $\begin{array}{l}50-59 \text { yr } \\
\text { (23 patients) }\end{array}$ & $\begin{array}{c}8 \\
(35 \%)\end{array}$ & $\begin{array}{c}9 \\
(39 \%)\end{array}$ & $\begin{array}{c}6 \\
(26 \%)\end{array}$ & 3.1 & 0.21 & 0.54 & 0.46 & 4.1 & 0.047 \\
\hline $\begin{array}{l}\geq 60 \mathrm{yr} \\
\text { (41 patients) }\end{array}$ & $\begin{array}{c}12 \\
(29 \%)\end{array}$ & $\begin{array}{c}25 \\
(61 \%)\end{array}$ & $\begin{array}{c}4 \\
(10 \%)\end{array}$ & 15.4 & 0.0005 & 0.60 & 0.40 & 11.8 & 0.0006 \\
\hline All HTs & 33 & 60 & 25 & 14.5 & 0.0008 & 0.53 & 0.47 & 13.3 & 0.0002 \\
\hline
\end{tabular}

The $\chi^{2}$ and $P$ values shown were obtained by comparing data for each category of HTs with values for the entire NT group used as control. $\chi^{2}$ analysis involved 2 d.f. for genotypes and 1 d.f. for alleles. Percentage values in brackets show the proportion of subjects having a particular genotype for that particular group.

$D D$. If $I I$ frequency is set at $100 \%$, and expected $D D$ values then calculated on the basis of the latter values, the $D D$ frequency that was observed in HTs aged $<50$ is $52 \%$, in HTs aged $50-59$ is $34 \%$, and for HTs aged $\geq 60 \mathrm{yr}$ is only $15 \%$ of the expected frequency. A similar comparison with actual frequencies obtained for the NTs, gave values of 47,31 , and $14 \%$ for the three respective age groups of HTs. In contrast, HT $I D$ frequencies showed little difference from expected values.

Relationship of I/D genotype with plasma ACE activity. Consistent with reports from studies by others of healthy Caucasian populations $(7,10,11,31)$ we found a highly significant difference in plasma ACE across each of the $I / D$ genotypes in our NT group (Fig. 1). In the case of Caucasian HTs the relationship of plasma ACE with $I / D$ genotype has not previously been examined by others. Our results showed that there was an almost identical pattern of tracking in the HTs examined as was observed in our NT group (Fig. 1). Moreover, mean plasma ACE was similar between the HT and NT groups and showed no correlation with BP (data not shown), whereas SBP and DBP

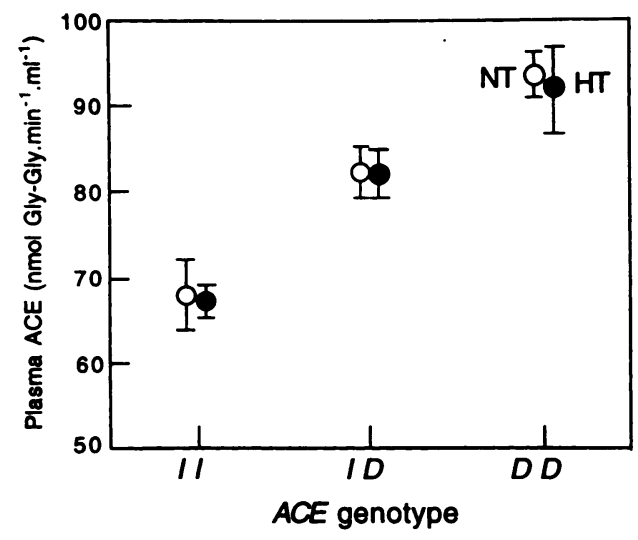

Figure 1. Plasma ACE activity vs genotype of the I/D polymorphism in 35 HTs $(\bullet)$ and 94 NTs $(O)$. Results for one-way ANOVA were: HT, $\mathrm{F}=4.0, P=0.027 ; \mathrm{NT}, \mathrm{F}=11, P=0.0001$.

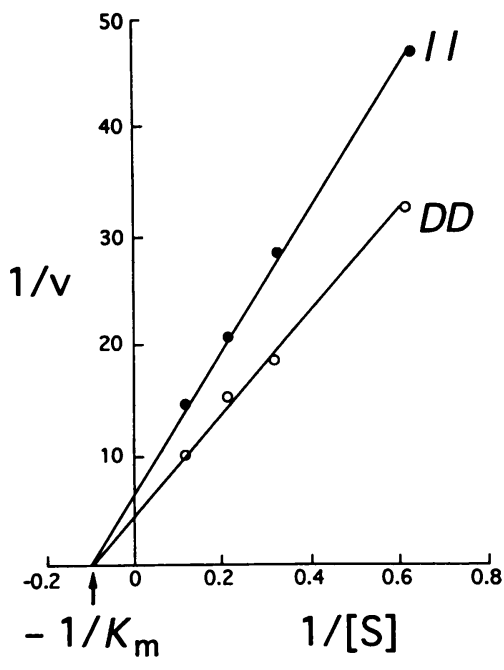

Figure 2. LineweaverBurk plot used to determine $K_{\mathrm{m}}$ of plasma ACE. This plot was produced from values for initial velocity (v) of plasma ACE activity $\left(\mu \mathrm{mol} \cdot \min ^{-1}\right.$ $\cdot \mathrm{ml}^{-1}$ ) for different concentrations of Hip-GlyGly substrate (S) $(\mu \mathrm{mol} /$ $\mathrm{ml}$ ) for a representative plasma sample from an $I I$ subject and one from a $D D$ subject.

for the combined groups showed a significant correlation with plasma angiotensinogen (C.L. Bennett and B.J. Morris, unpublished observations), so that if a relationship had existed between plasma ACE and BP it should have been detected.

Michaelis constant of plasma ACE encoded by I and D alleles. An example of Lineweaver-Burk plots for plasma ACE activity of representative $I I$ and $D D$ subjects is shown in Fig. 2. The coefficient of correlation for such lines of best fit for the 19 subject samples analyzed was close to unity $(0.995 \pm 0.001$ $\mathrm{SE}$, range $0.981-1.000)$. From such plots, $K_{\mathrm{m}}$ of plasma ACE for $D D$ subjects was $10.6 \pm 1.6 \mathrm{SE} \mu \mathrm{mol} / \mathrm{ml}(n=9)$ and for $I I$ subjects was $11.1 \pm 2.3(n=10)(P=0.9$ by $t$ test $)$.

Relationship of $\mathrm{LD}$ genotype with other parameters. By oneway ANOVA, values for SBP, DBP, BMI, and plasma lipids in each age group were similar across the three $I / D$ genotypes of HTs. Two-way ANOVA showed an absence of any relationship between sex and SBP or DBP for the different genotypes for the whole of the HT group, nor for any of the various age groups. Moreover, multiple regression analysis indicated no relationship of BP or BMI with age in any of the genotypes. There was, moreover, no apparent sex difference with respect to the decrease with age in $D D$ frequency seen in the HTs, although the numbers of $D D$ patients were small. Finally, BPs were similarly high in each age group and genotype of HTs.

\section{Discussion}

A population in Hardy-Weinberg equilibrium for a particular polymorphism should display genotype frequencies that remain stable throughout life. Any decrease observed for a particular genotype may suggest that alleles for that genotype carry an increased risk of mortality past the age of reproduction. The present cross-sectional study found an apparent age-dependent decrease in $D D$ frequency in a group of patients with severe, familial HT. It would be interesting if this apparent effect could be demonstrated by using the alternative approach of longitudinal analysis. However, this would take many years and could raise ethical concerns in view of the availability of ACE inhibitors that might offset any deleterious consequences arising in HTs as a consequence of having a $D D$ genotype.

It is unlikely that the results were a consequence of older HTs having a different form of HT, such as late-onset HT. 
Indeed, as described earlier, HT in all patients was in fact of early onset. This also argues against $I I$ being associated with a late-onset form of HT. In fact, no evidence has been produced by others for linkage (30) or association $(11,31,32)$ of the ACE gene with HT and in the present study BP was similar for each I/D genotype, whereas in the case of an unrelated gene in the present group, patients homozygous for a HT-associated variant had higher BP (29).

The present study did not address the question of cause of death of patients carrying the $D D$ genotype, nor could it, since we only studied living individuals. However, since HT was equally severe for patients of each genotype, on average BP by itself should have presented a similar cardiovascular risk to each genotypic subcategory. It is, however, impossible to say whether or not BP and/or plasma ACE were even higher in $D D$ HTs who were not included in the study because of their proposed early death.

Although plasma ACE correlates with BP in children (10), in whom it is claimed genetic effects may be easier to discern because of their higher rate of ACE synthesis $(4,9)$, we could find no such correlation in the adult subjects used in our study. The present findings for HTs thus extend earlier observations of a lack of correlation of BP with ACE genotype in NT adults (10). The implication is that $D D$ genotype is either not associated with higher circulating angiotensin II, or the pressor effects of raised angiotensin II in $D D$ patients may have been ameliorated by counterregulatory vasodilator and/or natriuretic mechanisms. Effects on parameters other than BP could, however, be occurring at a more localized level, in regional vascular beds of $D D$ /high ACE patients.

We also found that $K_{\mathrm{m}}$ of the ACE encoded by each allelic form of the gene was similar, so that variations in plasma ACE activity for the different genotypes are more likely to reflect differences in the concentration of ACE protein in plasma, as would result from differences in rate of synthesis or release by its cellular source.

If it is correct that the present results reflect an increased death rate amongst $D D$ HTs, then coronary heart disease must be considered as a possible candidate, as it accounts for $26 \%$ of all deaths in Australia (19). This possibility is, moreover, supported by findings of higher $D D$ frequency in MI patients $(11,13)$, those with a family history of fatal MI $(12,17)$, and in patients with related cardiac pathologies (14-16). The possible association of the $D D$ genotype with other potentially fatal events, such as stroke (10\% of fatalities) (19), other cardiovascular events $(9 \%)(19)$, or noncardiovascular diseases, remains to be explored. It is of interest that a pathological role of $D D$ in diabetic nephropathy (33) and hemodialysis (34) patients has also been proposed, so whether $D D$ is associated with renal disease in HTs remains to be explored.

The present results are consistent with expectations arising from findings by Cambien and others $(11-18)$, but, in apparent contradiction, a recent study has reported the unexpected finding of elevated $D D$ frequency in centenarians (35). In an attempt to reconcile the latter finding with emerging knowledge, these authors suggested that, in spite of being a risk factor for a leading cause of mortality, the $D D$ genotype might confer some early selective advantage, and the association with longevity may indicate a late reversal of its purported negative survival value. It has also been suggested that effects of higher ACE on myocardial cell growth could increase the incidence of MI and yet allow the left ventricle of a select few to carry them into advanced age (36). It was also suggested that involvement of $\mathrm{ACE}$ in a wide range of cellular functions may produce, in noncardiac tissues, beneficial effects that would have survival value should the person not succumb to a cardiac event. For example, higher ACE might improve repair of damaged tissues or increase resistance to neoplasia or infection via metabolism of peptides involved in the inflammatory response or antigen recognition (37). A further proposal is that the $D D$ variant may have a beneficial effect in neurones of the aged or could be serving as a marker for a hypothetical variant at the linked growth hormone gene locus that could perhaps have relevance to senescence (38). Another possibility is that DD/high ACE might have interactions with variants at other genetic loci that are also needed for an effect on overall death rate. Thus ACE may have both beneficial and deleterious functions, and the balance between each may change during the human lifetime.

In conclusion, this study has found a markedly reduced number of $D D$ genotypes among older HTs, possibly suggesting that homozygosity for the $D$ allele of the ACE gene might be associated with increased risk of premature death, at least in patients with severe, familial HT living in Sydney, who were not selected for cardiac pathology.

\section{Acknowledgments}

We thank Dr. L. R. Griffiths for help in recruitment of some of the HT volunteers used in this study, the Department of Clinical Biochemistry, Royal North Shore Hospital, Sydney for plasma lipid determinations, Dr. G. S. Stokes and Dr. J. C. Monaghan, Department of Clinical Pharmacology, for performing plasma ACE assays, and Dr. D. Mackerras, Department of Public Health, University of Sydney for critical epidemiological evaluation of the manuscript prior to submission.

This work was supported by a grant from the National Health \& Medical Research Council of Australia.

\section{References}

1. Ehlers, M. R. W., and J. F. Riordan. 1989. Angiotensin-converting enzyme: new concepts concerning its biological role. Biochemistry. 28:5311-5318

2. Soubrier, F., C. Hubert, P. Testut, S. Nadaud, F. Alhenc-Gelas, and P. Corvol. 1993. Molecular biology of the angiotensin I converting enzyme. I. Biochemistry and structure of the gene. J. Hypertens. 11:471-476.

3. Alhenc-Gelas, F., J. A. Weare, R. L. Johnson, and E. G. Eräos. 1983. Measurement of human converting enzyme level by direct radioimmunoassay. $J$. Lab. Clin. Med. 101:83-96.

4. Cambien, F., F. Alhenc-Gelas, B. Herbeth, J. L. Andre, R. Rakotovao, M. F. Gonzales, J. Allegrini, and C. Bloch. 1988. Familial resemblance of plasma angiotensin-converting enzyme level: the Nancy study. Am. J. Hum. Genet. 43:774-780.

5. Hubert, C., A.-M. Houot, P. Corvol, and F. Soubrier. 1991. Structure of the angiotensin I-converting enzyme gene. Two alternative promoters correspond to evolutionary steps of a duplicated gene. J. Biol. Chem. 266:15377-15383.

6. Mattei, M. G., C. Hubert, F. Alhenc-Gelas, N. Roeckel, P. Corvol, and F. Soubrier. 1989. Angiotensin converting enzyme gene is on chromosome 17. Cytogenet. Cell Genet. 51:1041.

7. Rigat, B., C. Hubert, F. Alhenc-Gelas, F. Cambien, P. Corvol, and F. Soubrier. 1990. An insertion/deletion polymorphism in the angiotensin I-converting enzyme gene accounting for half the variance of serum enzyme levels. $J$. Clin. Invest. 86:1343-1346.

8. Rigat, B., C. Hubert, P. Corvol, and F. Soubrier., F. 1992. PCR detection of the insertion/deletion polymorphism of the human angiotensin converting enzyme gene (DCP1) (dipeptidyl carboxypeptidase 1). Nucleic Acids Res. 20:1433.

9. Costerousse, O., J. Allegrini, M. Lopez, and F. Alhenc-Gelas. 1993. Angiotensin I-converting enzyme in human circulating mononuclear cells: genetic polymorphism of expression in T-lymphocytes. Biochem. J. 290:33-40.

10. Tiret, L., B. Rigat, S. Visvikis, C. Breda, P. Corvol, F. Cambien, and F. Soubrier. 1992. Evidence, from combined segregation and linkage analysis, that a variant of the angiotensin-I-converting enzyme (ACE) gene controls plasma ACE levels. Am. J. Hum. Genet. 51:197-205.

11. Cambien, F., O. Poirer, L. Lecerf, A. Evans, J. -P. Cambou, D. Arveiler, 
G. Luc, J. -M. Bard, L. Bara, S. Ricard, L. Tiret, P. Amouyel, F. Alhenc-Gelas, and F. Soubrier. 1992. Deletion polymorphism in the gene for angiotensin-converting enzyme is a potent risk factor for myocardial infarction. Nature (Lond.). 359:641 644.

12. Tiret, L., F. Kee, O. Poirier, V. Nicaud, L. Lecerf, A. Evans, J.-P. Cambou, D. Arveiler, G. Luc, P. Amouyel, and F. Cambien. 1993. Deletion polymorphism in the angiotensin-converting enzyme gene associated with parental history of myocardial infarction. Lancet. 341:991-992.

13. Zhao, Y., K. Higashimori, J. Higaki, A. Kamitani, M. Ohishi, T. Katsuya T. Miki, H. Mikami, T. Minamino, and T. Ogihara. 1994. Significance of the deletion polymorphism of the angiotensin converting enzyme gene as a risk factor for myocardial infarction in Japanese. Hypertens. Res. 17:55-57.

14. Raynolds, M. V., M. R. Bristor, E. W. Bush, W. T. Abraham, B. D. Lowes, L. S. Zisman, C. S. Taft, and M. B. Perryman. 1993. Angiotensin-converting enzyme $D D$ genotype in patients with iscaemic or idiopathic dilated cardiomyopathy. Lancet. 342:1073-1075.

15. Marian, A. J., Q. T. Yu, R. Workman, G. Greve, and R. Roberts. 1993. Angiotensin-converting enzyme polymorphism in hypertrophic cardiomyopathy and sudden cardiac death. Lancet. 342:1085-1086.

16. Ohishi, M., K. Fujii, T. Minamino, J. Higaki, A. Kamitani, H. Rakugi, Y. Zhao, H. Mikami, T. Miki, and T. Ogihara. 1994. A potent risk factor for restenosis. Nat. Genet. 5:324-325.

17. Bøhn, M., K. E. Berge, A. Bakken, J. Erikssen, and K. Berg. 1993. Insertion/deletion (I/D) polymorphism at the locus for angiotensin I-converting enzyme and parental history of myocardial infarction. Clin. Genet. 44:298-301.

18. Bøhn, M., K. E. Berge, A. Bakken, J. Erikssen, and K. Berg. 1993. Insertion/deletion (I/D) polymorphism at the locus for angiotensin I-converting enzyme and myocardial infarction. Clin. Genet. 44:292-297.

19. National Heart Foundation of Australia. 1991. Heart Facts 1991. National Heart Foundation, Sydney.

20. Zee, R. Y. L., L.-H. Ying, L. R. Griffiths, and B. J. Morris. 1991. Association and linkage analyses of restriction fragment length polymorphisms for the human renin and antithrombin III genes in essential hypertension. J. Hypertens. 9:825-830.

21. Ying, L.-H., R. Y. L. Zee, L. R. Griffiths, and B. J. Morris. 1991. Association of a RFLP for the insulin receptor gene, but not insulin, with essentia hypertension. Biochem. Biophys. Res. Commun. 181:486-492.

22. Zee, R. Y. L., Y.-k. Lou, L. R. Griffiths, and B. J. Morris. 1992. Association of a polymorphism of the angiotensin I-converting enzyme gene with essentia hypertension. Biochem. Biophys. Res. Commun. 184:9-15.

23. Zee, R. Y. L., B. J. Morris, and L. R. Griffiths. 1992. Association analyses of RFLPs for the $\alpha_{2}$ - and $\beta_{1}$-adrenoceptor genes in essential hypertension. Hypertens. Res. 15:57-60.

24. Zee, R. Y. L., L. R. Griffiths, and B. J. Morris. 1992. Marked association of a RFLP for the low density lipoprotein receptor gene with obesity in essentia hypertensives. Biochem. Biophys. Res. Commun. 189:965-971.
25. Zee, R. Y. L Y.-k Lou, L. R Griffiths, and B. J. Morris. 1993. Molecular genetic analyses of RFLPs for PCR-amplified growth hormone gene, renal kallikrein gene and atrial natriuretic factor gene in essential hypertension. Hypertens. Res. 16:113-120.

26. Morris, B. J., R. Y. L. Zee, L.-H. Ying, and L. R. Griffiths. 1993. Independent, marked associations of alleles of the insulin receptor and dipeptidyl carboxypeptidase-1 genes with essential hypertension. Clin. Sci. (Lond.). 85:189-195.

27. Herzog, H., L. A. Selbie, R. Y. L. Zee, B. J. Morris, and J. Shine. 1993. Neuropeptide-Y Y1 receptor gene polymorphism: cross-sectional analyses in essential hypertension and obesity. Biochem. Biophys. Res. Commun. 196:902-906.

28. Bennett, C. L., A. P. Schrader, and B. J. Morris. 1993. Cross-sectional analysis of $\mathrm{Met}^{235} \rightarrow$ Thr variant of angiotensinogen gene in severe, familial hypertension. Biochem. Biophys. Res. Commun. 197:833-839.

29. Zee, R. Y. L., Y.-k. Lou, and B. J. Morris. 1993. Insertion variant in intron 9 , but not microsatellite in intron 2 , of the insulin receptor gene is associated with essential hypertension. J. Hypertens. 11:1283-1288.

30. Jeunemaitre, X., R. P. Lifton, S. C. Hunt, R. R. Williams, and J.-M Lalouel. 1992. Absence of linkage between the angiotensin converting enzyme locus and human essential hypertension. Nat. Genet. 1:72-75.

31. Harrap, S. B., H. R. Davidson, J. M. Connor, F. Soubrier, P. Corvol, R. Fraser, C. J. W. Foy, and G. C. M. Watt. 1993. The angiotensin I-converting enzyme gene and predisposition to high blood pressure. Hypertension (NY). 21:455-460.

32. Schmidt, S., I. M. S. van Hooft, D. E. Grobbee, D. Ganten, and E. Ritz 1993. Polymorphism of the angiotensin I converting enzyme gene is apparently not related to high blood pressure: Dutch Hypertension and Offspring Study. $J$. Hypertens. 11:345-348.

33. Marre, M., P. Bernadet, Y. Gallois, F. Savagner, T.-T. Guyene, M. Hallab, F. Cambien, P. Passa, and F. Alhenc-Gelas. 1994. Relationships between angiotensin I converting enzyme gene polymorphism, plasma levels, and diabetic retina and renal complications. Diabetes. 43:384-388.

34. Nomura, H., I. Koni, Y. Michishita, T. Morise, and R. Takeda. 1994 Angiotensin-converting enzyme gene polymorphism in haemodialysis patients. Lancet. 343:482-483.

35. Schächter, F., L. Faure-Delanef, F. Gúenot, H. Rouger, P. Froguel, L. Lesueur-Ginot, and D. Cohen. 1994. Genetic associations with human longevity at the $A P O E$ and $A C E$ loci. Nat. Genet. 6:29-32.

36. van Bockxmeer, F. 1994. ApoE and ACE genes: impact on human longevity. Nat. Genet. 6:4-5

37. Costerousse, O., E. Jaspard, and F. Alhenc-Gelas. 1993. Molecular and genetic aspects of dipeptidyl carboxypeptidase-1 (the angiotensin-I converting enzyme)-expression in the immune system. Adv. Neuroimmunol. 3:217-226.

38. Editorial. 1994. Genetics of longevity and more trinucleotide repeats. Nature. (Lond.). 367:201.

39. Reavan, G. M., and B. B. Hoffman. 1989. Hypertension as a disease of carbohydrate and lipoprotein metabolism. Am. J. Med. 87(Suppl. 6A):6A-2S-6A$6 S$. 